\title{
Senderos de El capital en América Latina
}

\section{Jaime Ortega}

\author{
Departamento de Política y Cultura, Universidad Autónoma Metropolitana-Xochimilco \\ jaime_ortega83@hotmail.com
}

Titulo: Trails of The Capital in Latin America

Resumen: Se presenta una cartografía de las lecturas de El capital en América Latina a partir de grandes problemáticas. Así, historia y política son los grandes agregados a partir de los cuales se puede captar el devenir de un texto que atravesó múltiples senderos después de la revolución cubana. En la parte final se realiza un ejercicio de ejemplificación, partiendo de la propuesta de Alberto Parisí, uno de los pocos autores que ha pretendido realizar una lectura situada del texto de Karl Marx.

Palabras clave: El capital - capitalismo - geopolitica - Marx

\begin{abstract}
A cartography of the readings of The Capital in Latin America is presented based on major problems. Thus, history and politics are the great aggregates from which it is possible to capture the evolution of a text that crossed multiple paths after the Cuban revolution. In the final part, it is carried out an exercise of exemplification, starting from Alberto Parisí's proposal, one of the few authors who has tried to carry out a situated reading of Karl Marx's text.
\end{abstract}

Keywords: The Capital - capitalism - geo-politics - Marx

Recepción: 6 de noviembre de 2020. Aceptación: 15 de febrero de 2021

$$
* * *
$$


El capitulo sobre fetichismo de la mercancia en El capital es el Ulysses de nuestro tiempo.

Ricardo Piglia, Los diarios de Emilio Renzi.

...mientras que su ala más recalcitrantemente teórica insistía en seguir estudiando hasta la oclusión intestinal El capital.

Paco Ignacio Taibo II, El regreso de la verdadera araña

Aun no se ha realizado un rastreo exhaustivo de las veredas productivas que asumió la lectura de El capital en América Latina. Es cierto que en nuestra contemporaneidad son bien conocidas las principales interpretaciones y usos productivos que se han hecho del texto de "madurez" de Karl Marx en distintas escuelas del pensamiento. Conocemos en español las primeras intervenciones rusas, de la mano de V.I. Lenin y su estudio del desarrollo capitalista, los aportes de E. Pashukanis con respecto al derecho y el fetichismo jurídico y, ni qué decir, de las comentadas páginas de Isaak Rubin a propósito del valor y el fetichismo, dicho sea de paso, páginas a las que pudimos acceder gracias a la intervención teórica del grupo argentino Pasado y Presente, primero en Córdoba, después en México. En las décadas posteriores, marcadas a sangre y fuego por la disputa mundial en torno a la guerra, tenemos noticias de los trabajos de Roman Rosdolsky, cuando descubrió -y nos sigue ayudando a hacerlo- los Grundrisse, como momento clave de construcción categorial.

Si bien las décadas posteriores a estas primeras del siglo XX estuvieron enmarcadas por el crecimiento económico acelerado, con los consiguientes procesos de descolonización e industrialización, no se dejó de insistir en la importancia de El capital y este tuvo que convivir con otros motivos teóricos que ganaron centralidad. Los Manuscritos de 1844 fueron, sin duda, los protagonistas de muchos de los debates de la segunda mitad del siglo XX. Solo hacia finales de la década de 1960 tomó fuerza de nuevo la lectura del texto más famoso de Marx, asumiendo diversas veredas su tratamiento. De la mano de los "seminarios estratégicos" (como los llamaba Régis Debray) de Louis Althusser se colocó la consigna militante, pero también teórica que marcaría los esfuerzos intelectuales del futuro inmediato: ¡Leer El capital!

Con el francés y en su contra, surgen los acalorados debates sobre el estatuto de la obra de Marx, su unidad y sus momentos de quiebre. La presencia de Althusser moviliza muchos sentidos en la medida en que 
se aclara que no hay lectura inocente, pero tampoco lectura suficiente. Trabajar con El capital siempre orilló a imaginar nuevos formatos de pensamiento, no es casual que desde la Cuba revolucionaria Fernández Retamar (1967) señalara que el francés no indicó como deberían los poetas leer El capital. Nuevas escuelas y vertientes asoman en un escenario cada vez más marcado por la crisis capitalista, el agotamiento de la forma del capital hasta entonces dominante, y destapa vetas de interpretación.

Paralelamente, en Italia y Alemania aparecieron novedosas apreciaciones sobre la obra de Marx. Raniero Panzieri, Antonio Negri, Nicola Badaloni y Mario Tronti son sólo algunos de los nombres de los que exploraron dimensiones variadas de El capital. En Alemania, de manera confrontada, lo hicieron Wolfgang Fritz Haug, Michael Heinrich y Robert Kurz. De nuevo, estos son apenas unos pocos nombres de múltiples participantes de un debate cuya escala es global y que de ninguna manera se restringe al tradicional marco europeo.

Es legítimo preguntarse, ¿qué pasaba en las arenas teóricas latinoamericanas? ¿Se era incapaz de mostrar una productividad teórica? ¿Era el marxismo latinoamericano solo un aglomerado de panfletos y programas a propósito de realidades locales encerradas en sí mismas? ¿Nuestra "lucha de clases", tan atravesada por lo nacional, no permitía pensar la dimensión universal del despliegue del capital a partir de una de las exposiciones más certeras sobre dicha temática? Ha quedado claro, y en ello ha sido crucial el trabajo de Horacio Tarcus, que El capital tuvo una presencia de larga data en la región. A diferencia de otras zonas geográficas -y aquí hace falta, sin duda, una historia global de la traducción, circulación y recepción de El capital- la disputa por las traducciones se volvió también una permanente tensión por las formas de comprensión de la gramática marxista. La política práctica, con sus escalas estratégicas, no sólo no estuvo exenta de aquella discusión, sino que por momentos se volvió su centro y corazón.

Sin embargo, la preocupación central en este trabajo es mostrar algunas veredas que tuvo la recepción de El capital, destacando sus motivos productivos. Ello implica deslindar los formatos diferenciados con los que fue tratado, las tramas a partir de las cuales fue leído y los empleos, tanto metodológicos como explicativos. Se trata pues, más que de recepción o circulación, de productividad del discurso teórico.

Mostraremos ello a partir de varios apartados. El primero refiere a un conjunto de perspectivas que se desarrollaron en el continente en la época posterior a la revolución cubana, señalando puntos de anclaje clave; el segundo abordará, brevemente, una deriva de esos formatos de producción. 


\section{La raíz diversa de la apropiación de El capital}

Horacio Tarcus ha mostrado bien el itinerario de las traducciones de El capital en América Latina, incluidas no pocas disputas en torno a lo que significaba contar con lo que podríamos llamar un lenguaje marxista. Sin embargo, queremos pasar ahora a la productividad de los discursos de quienes se han enfrentado al texto y han producido a partir de él.

Se trata, por supuesto, de un ejercicio sintético, que no profundizará, aunque pretende registrar una cartografia inicial. En términos cronológicos nos colocamos después del "acontecimiento" de la revolución cubana. Esta rompe, definitivamente, el débil monopolio que sostenían algunos grupos -ligados al poder estatal soviético- en torno a la producción del marxismo. Como entramado teórico se perfiló en formas cada vez más novedosas, al tiempo que se vinculó con diversas trayectorias intelectuales y académicas, a veces acompañando a determinadas fuerzas políticas, a veces al margen de ellas; pero en general sosteniendo un estatuto de "autonomía relativa" frente a los cambiantes escenarios. Así, a un costado del marxismo en clave humanista, que sostiene una gran presencia en aquellas décadas, de a poco El capital va ganando un espacio en la reflexión teórica y política.

Podemos señalar las principales líneas de producción que asumieron este paradigma. La primera y más evidente es la que refiere a la historia del capitalismo, la forma en que se concibió su desarrollo y la necesidad de pensar experiencias locales dentro de un marco universal. El capital dejó de ser mirado como una obra a la cual había que acercarse en una clave historicista, es decir, atrapada en un tiempo y en un lugar. El capital, contrario a la versión canonizada por José Stalin, dejó de ser pensado como la narración del "capitalismo de libre competencia", cuyo centro era "la Inglaterra victoriana". Eso no significó que se dejaran lecturas en donde se hablaba de El capital como el ejemplo de la época "premonopolista" (Azcuy, 1983). Sin embargo, la operación teórica cambió, El capital no era sólo el relato de algo ya pasado en Inglaterra, sino una forma de pensar que demandaba a los marxistas de diversas nacionalidades pensar su propia realidad. Así podemos constatarlo en la mayor parte de quienes problematizaron las últimas secciones de la obra cumbre de Marx, encontrando en ellas reflexiones para pensar el estatuto capitalista de la región. Podemos señalar el pionero trabajo de Volodia Teitelboim (1979), presentado en 1946 como tesis de un intento de captar el lugar específico de la región sobre la base de las categorías entregadas en el texto de Marx.

A medio camino entre la historia y la discusión sobre el estatuto del capitalismo del siglo XX, podemos encontrar usos diversos de El capital. Por ejemplo, en la noción de "des-acumulación originaria" que el 
ecuatoriano Agustín Cueva (1977) compartió con el mexicano Enrique Semo (1973). Esta categoría, era una innovación teórica, que pretendió entender la conjunción de dos temporalidades históricas, la del capitalismo central que expropiaba localmente pero también expoliaba en territorios ultramarinos, reproduciendo o inaugurando procesos que después Marx captaría conceptualmente. Tanto Cueva como Semo eran parte de una pléyade de intelectuales ligados a las versiones de la militancia comunista.

De la misma forma es pertinente señalar a los historiadores que, desde diversas geografias, plantearon la necesidad de pensar la "acumulación originaria" no como un hecho ya estudiado en Inglaterra, en el pasado del centro capitalista, sino en su especificidad local y regional. Podemos mencionar casos diversos como el del boliviano Gustavo Rodríguez Ostria (1979), la colombiana Carmenza Gallo (1974), el chileno Marcelo Segall (1953) o el salvadoreño Rafael Menjivar (1983). Todos estos, pertenecientes a distintas tradiciones políticas, teóricas y disciplinares, expresaron la necesidad de captar la especificidad del capitalismo local. La historia servia, en todos estos casos, como un recurso al cual recurrir y mediante el cual el presente adquiría una tonalidad más cristalina, al estar enmarcado en procesos de "subdesarrollo" o "dependencia". Las formas nacionales que tomó el capitalismo -centrado en materias primas y con un fuerte componente oligárquico- obligó a pensar el estatuto de la "acumulación originaria" en territorios específicos y no sólo como un acontecimiento ya registrado en la teoría.

Otros, como el brasileño Carcanholo (1981), ensayaron desde la "teoría del valor", para el caso de Costa Rica, es decir que recurrian a un arsenal más amplio. Todos estos trabajos historizaban, más allá de las coordenadas tradicionales de la historia económica, y ponian a jugar a El capital en el escenario de las interpretaciones, no sólo del pasado sino también del presente. Cabría señalar que fue el hispano-soviético Anastasio Mansilla (1976) quien inauguró esta forma de comprensión a partir de sus Comentarios a la sección séptima de El capital desde la Cuba revolucionaria, en donde sus alumnos fueron, entre otros, Fidel Castro y Ernesto Che Guevara. Enviado a Cuba para ayudar a la formación teórica, Mansilla se destacó por su amplio conocimiento de El capital, pero también por abrevar de formas distintas a las que imperaba en el marxismo soviético del momento -por lo demás, irreductible al multi criticado "Dia-mat"-.

La dificultad que enfrentan algunos de estos textos, sobre todo los producidos por historiadores de formación más clásica, es la de distinguir los usos conceptuales. Si bien es claro que Cueva, Semo y otros se encuentran ya en diálogo con las ciencias sociales, existen casos donde se requiere una lectura atenta $y$, hasta cierto punto, imaginativa. Es 
el caso de los trabajos que involucran la existencia de un trabajo no asalariado. Por ejemplo, en Ramiro Cepero Bonilla -a la sazón, figura clave en la renovación del marxismo en Cuba- la presencia de Marx es importante. Quizá mas decididamente Marx se encuentra en El ingenio de Moreno Fraginals. El tema de la organización en la hacienda azucarera y el "barrancón" y todo lo que hay alrededor de la producción del azúcar es claramente una temática que convocó a los marxistas, en ella se juegan las fuerzas productivas técnicas y procreativas, las dimensiones políticas, la conformación del mercado mundial y otros tantos insumos. Caso contrario $-\mathrm{y}$ un tanto sorprendente puesto que colma las bibliografias contemporáneas de los marxistas- es el caso de Eric Williams (1975) quien no cita a Marx ni hace un uso categorial en su trabajo clásico. Esto, de ninguna manera disminuye su importancia, sólo es de llamar la atención. Algo similar sucede con el historiador chileno interesado en los problemas de la esclavitud (Mellafe, 1959). Quizá por las fechas de producción de estos trabajos, sea factible pensar que la noción de que El capital era un texto de historia de la economía inglesa -o alguna variante similar- contuvo su uso.

Sin embargo, no sólo la historia fue un campo en donde el texto de Marx descolló. Al paso de las décadas, las ciencias sociales se configuraron a partir de nociones extraídas de su corpus, tales como la subsunción real y formal, plusvalor absoluto, proceso de producción, entre otras. En el intenso debate en torno a las teorías de la dependencia destacaron dos plumas por ser las más refinadas en su apropiación de la obra de Marx: Ruy Mauro Marini y René Zavaleta Mercado. Ambos autores integraron al Marx de El capital en sus respectivas formulaciones teóricas, que se bifurcaban en cuanto a intereses. Mientras que el brasileño discurría sobre las formas de la dependencia a partir de la noción de superexplotación del trabajo (1973), el boliviano busca dimensionar la realidad estatal latinoamericana a partir de sus "cuatro conceptos de la democracia" (1982), en diálogo directo con El capital. El primero mantenía una lectura atenta de la combinación entre formas de extracción de plusvalor absoluto y plusvalor relativo, iniciando con ello una alternativa de comprensión de la "sociología del trabajo", en tanto que el segundo comprendía que los procesos de concentración y "centralidad técnica" del proceso productivo alteraban las dimensiones politicas de la vida contemporánea. El brasileño había pasado por experiencias proto-troskistas y se había vinculado fuertemente con el Movimiento de Izquierda Revolucionaria, en tanto que el segundo había evolucionado del nacionalismo revolucionario al marxismo, manteniéndose cercano al Partido Comunista Boliviano. Dos formas de comprender la politica, la revolución y la teoría; una más económica y la otra más política; ambas amparadas, en buena medida, sobre una lectura productiva de El capital. 
Otras veredas deben ser señaladas en un intento proceso de apropiación de la obra de Marx, en medio de fuertes olas represivas y de autoritarismo que hicieron sucumbir a gran parte de los espacios de reflexión. Por un lado, es pertinente señalar el papel de México como lugar de recepción de refugios que permitieron el acceso a la construcción de una veta del marxismo en clave de "crítica de la economía politica”. Entre los más destacados se encuentra Bolivar Echeverría (1986), Jorge Juanes (1982) y Armando Bartra (1979) como exponentes principales. En aquel espacio pasaron figuras como el ya mencionado Marini o Zavaleta, pero también el boliviano Carlos Toranzo (1983). En el recambio, en aquel espacio se formarian teóricos como Jorge Veraza y, en una prolongación, también Álvaro García Linera, de quienes hablaremos más adelante.

Hacia finales de la década de 1960 la entonces Escuela de Economía en México se convirtió en eje articulador de la institucionalización del marxismo. La Reforma al Plan de Estudios de 1974, resultado de un proceso de movilización y de tensiones con las autoridades universitarias, derivó en una "hegemonía" formal, la cual incluía numerosos cursos obligatorios de "Economía política", así como de "Transición del socialismo al capitalismo" y lo más importante, los "Seminarios de El capital". Ahí Bolívar Echeverría-quien venía de un paso intenso por el Berlín Occidental- dictaba curso en el Auditorio Ho-Chi-Mihn, Jorge Juanes hacia lo propio, ambos haciendo una lectura "linea por linea" del texto. Bartra profundizó en el tema agrario, tan candente para México, pero sin olvidar nunca las dimensiones teóricas más generales y que sólo muchos años después pudimos conocer en profundidad.

Esta clave de la "crítica de la economía política" permite también pensar en cómo el texto de Marx comenzó a procesarse en claves metodológicas o filosóficas, saltando de la "historia" como disciplina a un plano más abstracto. Así, Oscar del Barco (1977) produjo en su exilio mexicano Esencia y apariencia en El capital. Bolivar Echeverria, que venía de Alemania, produjo un conjunto de ensayos recopilados después en El discurso crítico de Marx. Enrique Dussel (1985), de Argentina a México, produjo una tetralogía. ${ }^{1}$ Cada una de estas producciones es distinta, pero se ancla en la idea de que Marx es, ante todo, un filósofo. O quizá, como Martínez Marzoa lo dijo en España, la filosofía de Marx es su crítica de la economía política. Del Barco lo hace desde una dupla que ha acompañado al marxismo desde sus origenes, vinculado al marxismo hegeliano, el autor argentino discute con una infinidad de autores sobre dimensiones como el saber absoluto, la crítica del mate-

1. Iniciada con La producción teórica de Marx (1985) y continuada con El último Marx, Hacia un Marx desconocido y Las metáforas teológicas de Marx. 
rialismo de Lenin o la concepción sobre el "modo de exposición". Sobre Echeverría y Dussel volveremos más adelante, ahora es preciso señalar que se enmarcó en el proceso de considerar a El capital no como una economía positiva, sino como una "crítica" en un sentido más filosófico. Ello implicaba movilizar distintos referentes. En el caso de Echeverría fue la lectura sistemática de los tres tomos, exponiendo que en cada uno de ellos se asumian distintos grados de exposición, tanto de esencia como de apariencia. Dussel, en cambio, redescubrió productivamente a Marx en su exilio mexicano, imponiéndose en sus cursos la tarea de leer lo que después denominaría "las cuatro redacciones de El capital", es decir, no considerar a este como un libro aislado e incompleto, sino como un proyecto.

Otro autor relevante en este entramado fue John Holloway, el irlandés avecindado en Puebla, que pasó de un estudio del Estado a entregar una perspectiva que apoyaba su reflexión en las categorías de El capital. Deudor y crítico de tendencias que se labraban en Europa Occidental, Holloway (2011) pasó de teorizar el Estado a pensar contra el Estado. ¿Podemos asimilar estos y otros trabajos en líneas generales a una tendencia? Sí, en la medida en que existen puntos de enlace a pesar de los distintos énfasis, al menos en algunos de los trabajos más significativos y que han generado mayor atención.

Por ejemplo, en Echeverría, Dussel y Holloway, que parten de horizontes muy diferenciados en sus fuentes teóricas, prima la idea de una "contradicción fundante" de todas las que se despliegan en el mundo moderno. En Echeverría esta "contradicción fundamental" recae sobre proceso de trabajo/proceso de valorización, aunque la mayor parte de sus comentaristas la han reflexionado como "valor/valor de uso". Remite a la existencia de una forma de sociabilidad y reproducción de la vida sobre la cual se impone otra, artificial y abstracta, pero dominante. Esta misma noción es la que prima en su concepción de la modernidad, que elaborará a partir de un diálogo entre la obra de Max Weber y Marx. En el caso de Dussel la contradicción fundamental es la de trabajo vivo/ trabajo muerto. Ella remite a la forma específica en que el argentino-mexicano lee a Marx a partir de Levinas, desde su punto de vista el capital y el trabajo asalariado son expresiones de la totalidad del orden social, en tanto que la exterioridad (es decir, lo no determinado) es el trabajo vivo. Esta lectura se apoya, fundamentalmente, en los Grundrisse de 1857, en donde Marx explícitamente trabaja la categoria de trabajo vivo como "no-capital". La operación de Dussel, al igual que la de Echeverría, se traslada del texto de Marx y pasa hacia una consideración global de la historia y la modernidad, en donde la europa colonialista es la totalidad y América Latina sería la exterioridad. En Holloway, la cuestión parte también de una contradicción fundante del resto: trabajo 
abstracto/trabajo concreto. Aunque, conforme su obra fue creciendo, encontramos una trasmutación de estas categorias hacia poder-hacer versus poder-sobre. Transformación que se implica tras el impacto del movimiento zapatista en su perspectiva teórica, en la que amoldó las categorias de Marx hacia versiones más pedagógicas. A diferencia de los otros, sin embargo, Holloway no deriva una teoria de la modernidad, ni tampoco una "filosofia de la historia". Se mantiene, por el contrario, en una idea de fundar una contrateoria, es decir una teoría en contra del Estado, una teoría en contra del dinero, ambas dimensiones serían las cristalizaciones más acabadas del poder-sobre, es decir, del trabajo abstracto. Ello decantará, al final, en su famoso texto Cambiar el mundo sin tomar el poder (2001), que debe ser leído como una forma específica de leer El capital de Marx.

Otros autores optaron por desarrollar la categoría de fetichismo, como en el caso del propio Echeverría en un breve texto, pero también el chileno Osvaldo Fernández (2016) -que pasó por México para después ir a Francia- y Carlos Aguirre Rojas (1984). Estos trabajos encontraron en el "fetichismo" de la mercancía algo más que un añadido a la teoría de la enajenación, problematizándola a partir de sus distintos niveles: la mercancía, el dinero y el capital. Es decir, mostraron cómo el fetichismo no era un concepto homogéneo, sino que requería especificidad en su análisis. Se trató de un motivo que movilizó la reflexión más allá de los marcos iniciales dados por Marx, pero buscaron profundizarlos. El fetichismo venía a complejizar y reemplazar las antiguas discusiones en torno a la ideología, la falsa conciencia y otros registros comunes en el marxismo de la primera mitad del siglo XX y mantenía una tensión con la categoría de enajenación. Sin embargo, de todos estos trabajos, el pionero fue el de Franz Hinkelammert (1977), al colocar un énfasis en la dimensión totalizante del fetichismo, con respecto al mercado, el poder y la subsunción real (recambio tecnológico y productivo). Hinkelammert, quien de Alemania pasó a Chile y de ahí, después de 1973, a Costa Rica, ha mantenido una línea de trabajo muy sugerente, en donde ha denunciado el "totalitarismo de mercado" y el fetichismo de la racionalidad que descansa sobre la "mano invisible", como verdaderas cruzadas contra la vida humana y la naturaleza. Además, en su más reciente etapa produjo en los últimos años uno de los trabajos más importantes en cuyo eje se encuentra la idea de la formulación de una "segunda crítica de la economía política".

La izquierda comunista también hizo sus aportes en este campo, aunque algunos fueron más limitados frente a las fuentes europeo-occidentales. Quizá menos elevadas en el nivel de refinamiento o en el diálogo con perspectivas como la "teoría crítica de la sociedad", pero con firmeza de superar los lugares comunes a los que se había condenado 
la obra de Marx tras la definición del "leninismo" hecha por Stalin. Así, encontramos los trabajos del chileno Sergio Vuskovic (1967), que fueron intentos de colocar a la izquierda comunista en el debate sobre El capital. Sin embargo, una de las perspectivas más relevantes se dio en México, en donde la antigua editorial del Partido Comunista -devenido a principios de la década de 1980 en Partido Socialista Unificado de México- editó la colección El capital: teoría, estructura y método, que conjuntó los esfuerzos más elaborados, tanto regionales como europeos, de discusión sobre el texto de Marx. Alguno de sus militantes, como Sergio de la Peña (1978) o Pedro López Díaz (1986), nutrieron distintas perspectivas conceptuales sobre la base del ejercicio de lectura de la obra madura de Marx. Los cuatro tomos son un ejemplo de la apertura y diálogo de los comunistas mexicanos, afincados en el trabajo político universitario, con corrientes más amplia del discurso marxista.

La lectura de El capital se diferenció porque no colocó el énfasis en las temáticas clásicas del marxismo humanista, anclado en los Manuscritos de 1844 y las "Tesis ad Feuerbach", como en el caso de la "filosofia de la praxis". Es plausible pensar que la relativa distancia de esta corriente con respecto a El capital viniera de la precaución ante el economicismo. Aún así, Adolfo Sánchez Vázquez publicó en la colección "Teoría y praxis" la obra de Jendri Zeleny, que era una lectura humanista de El capital, en una traducción que había realizado Manuel Sacristán en España. Respecto a la otra corriente fundamental en la segunda mitad del siglo XX, el "althusserianismo", esta produjo poco en torno a este tópico, salvo en los casos del mexicano Raúl Olmedo y del argentino Raúl Sciarreta. Aunque aquella corriente caló duro en la región, produjo poco con referencia al texto de Marx. Sin duda el trabajo de Marta Harnecker podría ser considerado, de alguna manera, una exposición de algunos tópicos que tocan los problemas de la crítica de la economía política, pero definitivamente no son una lectura pormenorizada, como las que hemos señalado.

El universo que hemos descrito aquí -apenas señalando algunas derivas- contiene algunas temáticas. No dejaron de existir problematizaciones que escapan a una reducción en alguna de estas cuestiones. Aunque también sean relevantes. Es el caso de obras como la del argentino peronista Norberto Wilner (1969), que, en un ambicioso trabajo, buscó develar en el tomo primero de El capital la categoría de "ser social"; o la del boliviano Carlos Toranzo, quien en un texto florido y habitado por múltiples metáforas (1983), propuso una lectura epistemológica, es decir, centrada en el problema del método, la delimitación de su objeto y las formas de operar del pensamiento. Trato similar al que dio el profesor y dirigente socialista ecuatoriano Manuel Agustín Aguirre (1962), el peruano Guillermo Rochabrún (1974), el venezolano 
Núñez Tenorio (1976), el dominicano José Oviedo (1980) o el mexicano Enrique de la Garza (1983). En todos estos autores, El capital contenía un método especial, que había que explicitar. Asimismo, Oscar Correas, argentino-mexicano, trabajó una lectura de El capital (1982) en clave de crítica jurídica, en un esfuerzo que por momentos fue solitario. Otro solitario fue Wim Dierckxsens (1982), quien desde conceptos como forma valor analizó los problemas de la reproducción de la fuerza de trabajo. Aunque producidos en Brasil -que ameritaria, como suele suceder con el país-continente, un trabajo aparte- los trabajos de Paul Singer fueron de gran valía al lector en el resto del continente, en temas introductorios a las categorías de El capital (1985) pero también en dimensiones de la fuerza de trabajo (1981) y la urbanización (1975).

Es pertinente, también, señalar la existencia de las distintas posibilidades que existen, superando el regionalismo, de mirar cruces y miradas. Es el caso de la producción de Ernesto "Che" Guevara, que, a modo de apuntes (2006), dejó su huella en la lectura de Marx. Se trata de un episodio significativo, más que por las dimensiones de su reflexión, por el tipo de trabajo: eminentemente práctico y enfocado en la resolución de problemas concretos. Sin embargo, ello no impidió que el revolucionario argentino sostuviera un intenso debate en el que terciaron Ernest Mandel y Charles Bettelheim. Esa estela problematizaba un viejo tema surgido con la revolución soviética y ampliado con la emergencia de China -con el economista francés mencionado como mediador- en el horizonte mundial: el tipo de categorias que debian operar en la economía de transición. Este es, quizá, el tema más práctico de las derivas que tuvo la lectura de El capital: convocó la experiencia clásica de la revolución rusa, saltó hacia China por medio de la traducción conceptual en Francia por parte de Bettelheim (en menor medida de Balibar) y dio sentido a las discusiones en los primeros años de la Cuba revolucionaria y del Chile de Allende, por ejemplo en los trabajos de Sergio Ramos (1972), aunque no exclusivamente de él.

Las coordenadas políticas e ideológicas comenzaron a transformarse en la década de 1980. Aunque algunas de las producciones citadas se presentaron en esta época, forman parte, conceptualmente, de un periodo previo, marcado por la idea de revolución, el predominio del marxismo y el diálogo con tendencias político-militantes. Como lo ha demostrado López Nájera (2018) vivimos en la región una "Derrota política, [una] crisis teórica y transición epistémica". Esto desplazó al marxismo, en algunos países con los procesos de transición temprana -Argentina y Brasil-y en otros en el largo proceso -Chile y México- que imbricó con la caída del Muro de Berlín. El marxismo como corriente teórica eclosionó, por un lado quedaron los grupos militantes, anclados en sus certezas, aunque muy disminuidos, y por el otro un conjunto de voces, la mayor 
parte reducidas al mundo universitario, que continuaron intentando trabajar.

En este nuevo entramado tenemos algunas novedades. Por ejemplo, los trabajos de Juan Iñigo (2007), que han ganado centralidad entre grupos que quieren volver a El capital sin grandes sobresaltos ni innovaciones teóricas, con un lenguaje clásico bien asentado en una tradición política. Néstor Kohan (2001) hizo lo propio, con una intencionalidad pedagógica y política. En Colombia se revivió cierta discusión en torno al texto, tanto por la obra de Luz Teresa Gómez (2014), quien se aproxima a El capital con una mirada sociológica (colocando énfasis en las clases sociales). Respecto de la teoría de la dependencia, algunos han continuado trabajando con sus categorias, como es el caso de superexplotación del trabajo (Osorio, 2004) o crisis (Sotelo Valencia, 2010). En términos filosóficos, con una alta originalidad, el texto de Carlos Oliva (2013) representa una apuesta por enlazar la lectura de Bolivar Echeverría de El capital con la semiótica, colocando el problema de la "forma natural" en relación con las representaciones de segundo orden, es decir, con la perspectiva técnica.

De este material contemporáneo vale la pena destacar dos producciones. La primera es la de Álvaro García Linera, que, a su paso por México, tuvo contacto con los espacios de lectura de El capital, como ha sido señalado en una reciente entrevista de gran valía. Esa forma de trabajo redituó, ya en la década de 1990, en la elaboración de Forma valor, forma comunidad, un texto mayormente ubicado en un grado de abstracción amplio, que sólo al final habilita una discusión más histórica de la formación del marxismo. Se trata, sin lugar a duda, de un texto clave para entender la productividad de Marx en la región y es, también, una respuesta a nuevas cuestiones, particularmente la de los problemas alrededor de la comunidad. La segunda es la de Jorge Veraza, a quien hemos mencionado antes. Su marxismo, como ha sido destacado (Valerio, 2020) es una apuesta por una reconstrucción teórica. Ello le ha implicado fases diversas, por ejemplo, la crítica del imperialismo como una categoría que sustituya a las contenidas en El capital (Veraza, 1987), una ejemplificación (en gran medida contra Althusser) de cómo leer $\mathrm{El}$ capital, linealmente y como un todo armónico (2007), su exposición de una teoría de las fuerzas productivas no técnicas (2012). Y quizá, uno de los aportes más originales, el traslado de las categorias de subsunción real a la esfera del consumo (2008).

Hemos eludido aquí mencionar la gran bibliografia que existe sobre problemas exclusivamente económicos, es decir, ubicada en el tránsito de valores en precio o debates similares. La comunidad académica marxista en el campo económico es importante y muy vital, la labor de Mario Robles ha dejado textos muy relevantes a propósito de la dialéctica 
(Robles, 2005) y su relación con el dinero y el capital (Robles y Escorcia, 2016). Sin olvidar, por supuesto, el trabajo como economistas críticos de realidades concretas de José Valenzuela, Claudio Katz, Rolando Astarita, Abelardo Mariña, Marcelo Carcanholo, Juan Kornblihtt, Marina Machado o Renán Vega Cantor, por mencionar solo algunos.

Después de este recuento podemos pensar que El capital ocupó un lugar importante en el discurso marxista, al menos después de 1959 con mayor claridad. Sin embargo, es preciso insistir en al menos un ejemplo de este tipo de lectura. Hemos seleccionado una producción argentina, aparecida en 1988, comprometida con el ambiente revolucionario de décadas pasadas. Se trata de la obra Una lectura latinoamericana de El capital de Alberto Parisí. Texto poco conocido, de escasa circulación, pero que permite ilustrar una forma particular del recorrido que hemos hecho antes.

\section{Una deriva de la lectura: Alberto Parisí como ejemplo}

La lectura de Dussel sobre Marx ha sido en múltiples ocasiones abordada, comentada y criticada, por distintos motivos, ya sea su relación con las filosofias de la liberación, ya sea por su intento de realizar un diálogo entre la categoría de exterioridad y la de totalidad, es decir, entre Levinas y Marx. Yo mismo inicié un ejercicio (Ortega, 2018) comparativo con Echeverría. En este apartado final, aprovecharé para señalar una hipótesis: la deriva que tuvo la obra de Dussel en una lectura realizada en Argentina a cargo de Alberto Parisí.

Ha sido Christian Gauna (2016) quien ha presentado los datos fundamentales de este autor, muy poco revisitado en las historias del marxismo en la región y más focalizado en su relación con la filosofia de la liberación, gracias a su trabajo Dialéctica y Filosofía. Después de cursar filosofia en la Universidad de Cuyo, como tantos otros de su generación, tuvo que ir al exilio. En México su estancia resulta compleja, dada una situación laboral cambiante, que finalmente logra cerrar con su adscripción en la Universidad Pedagógica Nacional. De regreso a Argentina su producción no descansa y continúa. Aquí es donde se ubica su incursión en El capital, que tendrá una fuerte carga dialéctica y ontológica. Parte de su actividad se encuentra en un emprendimiento de tipo ideológico político, como fue la revista Alternativa Latinoamericana (Barón del Pópolo, 2016).

Su planteamiento resulta original en la medida en que propuso una Lectura latinoamericana de El capital (Parisi, 1988), aunque en gran medida se trata de una vuelta de tuerca de algunos planteamientos de Dussel. Parisí elaboró su propuesta a partir de las demandas del movimiento popular impactado por la revolución sandinista. En dicho 
proceso revolucionario, como se recuerda, la noción de pueblo pareció ganar espacio, frente a la lectura clasista, asociada comúnmente con el esquematismo "ortodoxo".

Del conjunto del texto destacamos el señalamiento de la condición situada de su ejercicio:

Más allá de los muchos desaciertos o falencias que nuestra interpretación pueda contener, algo es claro a lo largo de toda nuestra lectura: dialogaremos con el pensamiento de Marx, asumiendo como "norte" de nuestra preocupación no a Marx o a El capital, sino nuestra propia e insoslayable realidad. (Parisí, 1988, p. 7)

Esto resulta clave, pues en la amplia gama de trabajos que se hicieron sobre Marx, pocos fueron los que explícitamente encaminaron su tarea por este sendero.

A esta declaración de principios sigue una exposición sobre el estatuto teórico de El capital. El principio está en aclarar que no es un libro "de economía", sino "una crítica de la economía política" (Parisí, 1988, p. 10). Sin embargo, delimitar El capital como un proyecto de crítica no da espacio para que, como sucede con Dussel, actúe una consideración más amplia de qué es lo que compone ese proyecto. Recuérdese que en este último autor El capital no es un libro, sino un conjunto de libros, que se inician en los Grundrisse y que abarcan la edición tradicional de El capital y otros tantos manuscritos, como los fechados en 18611863. Parisí, cercano a Dussel, no adhiere a esta perspectiva, pero sitúa la obra de Marx como una "crítica" y no como una economía positiva.

Llegado a este punto debe justificar el subtítulo: ¿una lectura latinoamericana? ¿qué especificidad podría tener este tipo de aproximación? Al igual que Dussel, Parisí sitúa el entramado problemático en un devenir, resultado de "nuestra peculiar situación geopolitica, histórica y cultural" (Parisí, 1988, p. 12). El capital nació en una geopolítica del conocimiento y la lectura que se propone se da en otra, marcada por la crisis del marxismo y la revolución popular sandinista. Así, ahonda:

Desde esa condición concreta queremos interrogar a $\mathrm{El}$ capital, y no desde una abstracta situación universalista; interrogarlo para saber en qué medida sus concepciones, su crítica, su visión de la sociedad tienen hoy vigencia para nosotros y nos permite comprender nuestra realidad. (Parisí, 1988, p. 12)

Este reconocimiento lo lleva entonces a desmarcar su ejercicio frente a otros. El suyo, dice, considera que El capital es una "obra abierta", y en ese sentido "urge al lector a un esfuerzo adicional de imaginación 
crítica y renovado trabajo de reflexión y estudio" (Parisí, 1988, p. 13). Desde su carta de intención del formato que debe tener una lectura situada de El capital, Parisí señala nodos sugerentes: "la estructura del Modo de Producción capitalista (MdPc), en el cual hemos surgido como países explotados, subdesarrollados y dependientes" (p. 14); "los fenómenos de explotación y la lucha de clases, consustanciales a este MdPc" (p. 15), y también "el carácter peculiar de las relaciones y la cultura" (Parisí, 1988, p. 15).

Excediendo al prólogo, la exposición continúa desarrollando nociones de la crítica de la economía política y su significado. Para lo cual remite al problema de los distintos "planes" que Marx elaboró en diversas ocasiones. Ello le permite profundizar en algunas nociones, como la de obra "abierta", que se muestra para él a partir de "los cambios profundos introducidos en el plan original y las dudas, avatares y dificultades que impidieron a Marx proseguir la publicación de su obra más allá del tomo I" (Parisí, 1988, p. 22). Así, la apertura, aclaró Parisí, ocurre en el interior de la obra, pero también en su carácter inconcluso, y en planteamientos provisorios, que deben ser profundizados (Parisí, 1988, p. 364).

Pasando revista al plan de los seis libros, los cambios de estos por parte de Marx y el material con el que se dispone efectivamente, desarrolla -siguiendo en gran medida la ya mencionada obra de Jorge Juanes- la estructura argumental del Tomo I. En este encuentra que Marx busca desarrollar la categoría de capital "como la realidad o elemento distintivo en ese macroproceso histórico y social llamado Modo de Producción capitalista" (Parisí, 1988, p. 26). Así, plantea que en la sección primera esta la "esencia" de todo El capital. Define, además, algo que para otras vertientes resulta problemático: el carácter transhistórico de la exposición de la mercancía. Para él, lo analizado en la sección primera "es válido [...] para todas las sociedades productivas de mercancías, incluido el MdPc" (Parisí, 1988, p. 27).

Que todas las sociedades en donde haya existido la mercancía puedan explicarse, desde su perspectiva, a partir de la sección primera, le obliga a definir qué es lo específico del aporte de Marx. Así, sanciona, "vale la pena puntualizar algo: lo realmente inédito en el análisis marxiano de la mercancía estriba en haber descubierto la "forma de valor", es decir, haber descubierto que el valor es una relación social e histórica" (Parisí, 1988, p. 31). Aparejado a estas definiciones, Parisí se suma al corpus de autores que reivindican el carácter dialéctico de la reflexión de Marx, contenida en El capital, lo cual explica, entre otras cosas, su aversión hacia Althusser. Desde su punto de vista el "fondo dialéctico" del texto, determina la esencia de su estructura, pero también su método, sus formatos teóricos y, finalmente, la crítica que permite realizar. Separarse 
de la dialéctica es algo que no concibe como viable: "desligarlo del mismo [fondo dialéctico] es causarle una amputación esencial e irreversible" (Parisí, 1988, p. 38).

Finalmente, su trayecto lo lleva a desligarse de la versión canónica -al menos desde Stalin- que encarcela la reflexión de El capital a un conjunto de ejemplos históricos: el capitalismo del XIX, la libre competencia o la Inglaterra victoriana. Para Parisí, el texto se encuentra más allá de coordenadas históricas, pues remite no a la historia del desarrollo del capitalismo y de un "recuento de sus principales problemas concretos (aunque contenga partes históricas), sino la exposición lógico-dialéctica de la específica racionalidad de dicho Modo de Producción" (Parisí, 1988, p. 40).

Por más de 400 páginas Parisí ensaya una aproximación a los tres tomos de El capital. Primero, copia un pasaje largo que muestra alguna problemática. Posteriormente incluye un "comentario" en el cual explicita la problemática, la importancia que tiene el pasaje citado y lo que este muestre en el conjunto de la crítica de Marx. Capitulo por capítulo replica esta operación. Hacia el final de cada sección da una conclusión general y presenta una serie de preguntas y temas que podrian ser discutidas de manera colectiva. Igualmente, sugiere bibliografia, de acuerdo a distintas temáticas contenidas en la sección correspondiente.

Ahora bien, podemos ya demarcar algunas de las principales tendencias interpretativas que habitan el texto.

El énfasis colocado por Parisí de ir capítulo por capítulo puede ser interpretado como un ejercicio pedagógico. No es que Parisí quisiera construir una interpretación disruptiva del campo marxista. Tampoco entregar su propia interpretación, que abonara en concepciones más amplias, como el estatuto de la política, el Estado o la modernidad. Parisí se centra en el texto porque muestra la intención de aprender con otros sobre ese texto y no sobre algo más.

Es posible preguntarse por el estatuto de la productividad del ejercicio de la "forma-comentario", que Althusser consideraba como una "lectura religiosa", en su crítica a Sartre y otros. Nuestra evaluación es que Parisi ejercer una sugerente productividad en el entramado, aquel donde no se encierra en el texto; así, su consideración global de El capital como una obra de crítica y no como una forma de economía positiva, su consideración del carácter "abierto", su disposición sobre la dialéctica como algo más que un estilo de presentación, abonan a pensar eso. El grueso del trabajo, al seguir el comentario puntual, deja en suspenso la productividad. La pretensión del título: presentar una "lectura latinoamericana", queda entre dicho. Algo se asoma en los ejercicios de reflexión, en donde las condiciones sociales y políticas aparecen, pero de forma muy minoritaria. 
Sin embargo, el esfuerzo no resulta fútil. Un año después de la aparición del libro, Parisí publicó el texto "Deuda y capitalismo" (1989) en la revista Alternativa Latinoamericana, ya referida. Ahí, hablando de la pesada losa que significaba la deuda externa, Parisí aventura una serie de hipótesis sobre la comprensión de ese fenómeno económico y geopolítico. La explicación en ese texto remite a que los niveles más concretos del análisis de Marx, particularmente los del tomo tercero, son los que permiten entender la deuda como un fenómeno de la construcción del mercado mundial. Parisí encuentra que algo que Marx detecta como contingente -la plusganancia en el comercio colonial- se vuelve la norma en la época de las relaciones centro-periferia. Si consideramos ambos textos, es posible pensar que el largo comentario entregado en 1988 es apenas la apertura para pensar las condiciones geopoliticas de las nuevas relaciones entre centro-periferia que se observan como candentes en la "década perdida", signada por la implantación, a sangre y fuego, del neoliberalismo.

\section{Aproximaciones finales}

El trabajo que presentamos tuvo dos frentes. En el primero expusimos largamente sobre distintas lecturas de El capital. Apenas como una pequeña pincelada, demostramos las múltiples derivas más allá de la economía como disciplina institucionalizada. Nos referimos a énfasis históricos, políticos y filosóficos. La geografia de la recepción de El capital está por realizarse y esta es una pequeña contribución, que, esperemos, siente las bases para un ejercicio menos general. Nos interesó ello porque durante mucho tiempo la obra madura de Marx tendió a ser sometida al dictum historicista de que ella correspondia a la exposición de una etapa histórica (el siglo XIX, el capitalismo de libre competencia) o una escala geográfica (Inglaterra). De alguna manera resulta plausible pensar que muchos economistas prefirieron el término de imperialismo, pues ello les permitía trabajar con nociones empíricas propia de su disciplina, como la del capital monopolista. El capital ocupó otros registros, más variados y en diálogo-confrontación con la economía.

Nos resultó sugerente incluir hacia el final un pequeño apartado sobre una obra que se propuso, explícitamente, realizar una lectura de El capital, como fue la de Parisí. La situamos, claramente, como un ejercicio derivado de la propuesta "dusseliana" de lectura de las obras de Marx. Expusimos su cometido y encontramos una doble perspectiva. A lo largo del texto observamos un fuerte énfasis pedagógico, lo que no es menor en la tradición de la teoría social latinoamericana y, en segunda medida, una forma -minoritaria-de pensar El capital como un insumo para perspectivas nacional-populares. En esta última destaca la transfe- 
rencia de valor de capitales nacionales débiles a otros más fuertes. Más allá de las variaciones, tanto en la pedagogía como en su uso político, hay un planteamiento claro de diálogo con la realidad.

\section{Referencias}

Aguirre, M. (1962). Los clásicos y Marx, t. II. Editorial Universitaria.

Aguirre Rojas, C. (1984). El problema del fetichismo en El capital. UNAM.

Azcuy, A. (1983). Capitalismo premonopolista: curso introductorio a El capital. Editorial de Ciencias Sociales.

Barón del Pópolo, G. (2016). La intuición de una América Latina. Entrevista a Rolando Concatti sobre la revista Alternativa Latinoamericana. Pelicano, 2, 146-155.

Bartra, A. (1979). La explotación del campesino por el capital. Macehual.

Carcanholo, R. (1981). La transferencia de valor y el desarrollo del capitalismo en Costa Rica. Tesis en la UNAM.

Carrera, I. (2008). El capital: razón histórica, sujeto revolucionario y conciencia. Imago Mundi.

Correas, O. (1982). Introducción a la crítica del derecho moderno: Esbozo. UAP-UAG.

Cueva, A. (1977). El desarrollo del capitalismo en América Latina. Siglo XXI.

De la Garza, E. (1983). El método concreto-abstracto-concreto. UAM-I.

De la Peña, S. (1978). El modo de producción capitalista: teoría y método de investigación. Siglo XXI.

Del Barco, O. (1977). Esencia y apariencia en El capital. UAP.

Dierckxsens, W. (1980). Capitalismo y población. Nuestro Tiempo.

Dussel, E. (1985). La producción teórica de Marx. Siglo XXI.

Echeverría, B. (1986). El discurso crítico de Marx. Era.

Fernández, O. (2016). Del fetichismo de la mercancía al fetichismo del capital (1982). Ideas.

Fernández, R. (1967). Ensayo de otro mundo. Instituto del Libro.

Gallo, C. (1974). Hipótesis de la acumulación originaria de capital en Colombia. Editorial Pulga.

Gauna, C. (2018). Alberto Parisí. Perfil bio-bibliográfico en perspectiva latinoamericana, Cuadernos del CEL, 6, 223-239.

Gómez, L. (2014). La sociología en El capital de Karl Marx. Universidad Nacional de Colombia.

Guevara, E. (2006). Apuntes críticos a la economía politica. Ocean Sur.

Hinkelammert, F. (1977). Las armas ideológicas de la muerte: el discernimiento de los fetiches, capitalismo y cristianismo. DEI.

Holloway, J. (2001). Cambiar el mundo sin tomar el poder. Herramienta.

Holloway, J. (2011). Agrietar el capitalismo. Herramienta.

Iñigo, J. (2007). Conocer el capital hoy: La mercancía, o la conciencia libre como forma de la conciencia enajenada. Imago Mundi. 
Juanes, J. (1982). Marx o la critica de la economía politica como fundamento. UAP.

Kohan, N. (2001). El capital. Historia y método: una introducción. UMPM.

López Díaz, P. (1986). La crisis del capitalismo: teoría y práctica. Ediciones de Cultura Popular.

López Nájera, V. (2018). Derrota politica, crisis teórica y transición epistémica. UNAM.

Mansilla, A. (1976). Comentarios a la sección séptima del tomo 1 de El capital. Editora Política.

Mantina, L. (2014). La sociología en El capital de Marx. Universidad Nacional de Colombia.

Marini, R. (1973). Dialéctica de la dependencia. Era.

Mellarfe, R. (1959). La introducción de la esclavitud negra en Chile. Editorial Universitaria.

Menjivar, R. (1983). Acumulación originaria y desarrollo del capitalismo en El Salvador. Educa.

Núñez Tenorio, R. (1976). Problemas de la teoría y el método de la economía politica marxista. UCV.

Oliva, C. (2013). Semiótica y capitalismo. Ítaca.

Ortega, J. (2018). Leer El capital, teorizar la politica. UNAM.

Osorio, J. (2004). Critica de la economía vulgar. UAZ

Oviedo, J. (1980). Génesis y desarrollo del problema metodológico en Marx. Poder Popular

Parisí, A. (1988). Lectura latinoamericana de El capital. Letra.

Parisí, A. (1989). Deuda y capitalismo. Alternativa latinoamericana, 9, 3-7.

Patriglia, J. (2020). Siempre hablo de un marxismo situacional. Entrevista a Álvaro García Linera., Religación, 26, 236-25.

Ramos, S. (1972). Chile ¿Una economía en transición? Casa de las Américas.

Robles, M. (2005). Dialéctica y capital: Elementos para una reconstrucción de la critica de la economía politica. UAM-X.

Robles, M. y Escorcia, R. (2016). Dinero y capital: hacia una reconstrucción de la teoría de Marx sobre el dinero. UAM-X.

Rochabrún, G. (1974). La metodología en el positivismo y en el marxismo: a partir de la 1 ra. sección de El capital. INTEC

Rodríguez Ostria, G. (1979). La Acumulación originaria de capital en Bolivia (1825-1885). Universidad Mayor de San Andrés.

Segall, M. (1953). Desarrollo del capitalismo en Chile: cinco ensayos dialécticos. Editorial Pacífico.

Semo, E. (1973). Historia del capitalismo en México. Era.

Singer, P. (1975). Economía politica de la urbanización. Siglo XXI.

Singer, P. (1980). Economía politica del trabajo: Elementos para un análisis histórico-estructural del empleo y de la fuerza del trabajo en el desarrollo capitalista. Siglo XXI.

Singer, P. (1985). Curso de introducción a la economía politica. Siglo XXI. 
Sotelo Valencia, A. (2010). Crisis capitalista y desmedida del valor: un enfoque desde los Grundrisse. Ítaca.

Tarcus, H. (2019). La biblia del proletariado. Traductores y editores de El capital en el mundo hispanohablante. Siglo XXI.

Teitelboim, V. (1979). El amanecer del capitalismo y la conquista de América (1946). Casa de Las Américas.

Toranzo, C. (1983). La dificultad de prologar "El capital”. UAM-X.

Valerio, D. (2020). El marxismo de Jorge Veraza como una reconstrucción crítica de la teoría marxista. Disertaciones, 2, 37-57.

Veraza, J. (1987). Para la critica a las teorias del imperialismo. Ítaca

Veraza, J. (2007). Leer El capital hoy: pasajes selectos y problemas decisivos. Ítaca.

Veraza, J. (2008). Subsunción real del consumo bajo el capital. Ítaca.

Veraza, J. (2012). Karl Marx y la técnica desde la perspectiva de la vida: para una teoria marxista de las fuerzas productivas. Ítaca.

Vuskovic, S. (1967). Los primeros cien años de El capital. ICAL.

Wilner, N. (1969). Ser social y tercer mundo. Galerna.

Williams, E. (1975). Capitalismo y esclavitud. Ciencias Sociales.

Zavaleta Mercado, R. (1982). "Cuatro conceptos de la democracia". Dialéctica, 12, 11-30. 